\title{
Phosphorus as a Lunar Volatile
}

\author{
Matthew A. Pasek \\ School of Geosciences \\ University of South Florida
}

NES 207

4202 E. Fowler Ave

Tampa FL 33620

Phone: 813-974-8979

Email: mpasek@usf.edu

\begin{abstract}
:
Phosphorus is an important minor element on the Moon. It is moderately volatile and is found as both phosphates and phosphides in lunar material. The phosphides, such as schreibersite, are common to impact breccias at all Apollo sites. The origin of this schreibersite has been proposed to be a meteoritic contaminant, or alternatively produced in situ by reduction on the lunar surface. I propose that schreibersite and other siderophilic $\mathrm{P}$ phases have an origin from impact volatilization of phosphates at the lunar oxygen fugacity, followed by reaction of $\mathrm{P}$ gases with metal to form metal phosphides. This pathway is broadly consistent with the composition and structure of metal grains, as well as the native oxygen fugacity of the lunar surface. Additionally, this pathway suggests schreibersite is widespread across the lunar surface and likely on other planetary bodies, and hence may serve as a good P source for in situ resource utilization.
\end{abstract}

Keywords: Lunar, volatile, phosphide, phosphorus, reduction 


\section{Introduction}

Phosphorus $(\mathrm{P})$ is a moderately volatile element, as it condenses after the formation of iron-nickel metal in the cosmochemical sequence (Fegley and Lewis 1980) at about $1300 \mathrm{~K}$ at $10^{-4}$ bar of pressure (Pasek 2008). Relative to other volatiles, $\mathrm{P}$ is not appreciably volatile as there are no significant $\mathrm{P}$ gases, such as $\mathrm{PH}_{3}$, at any rocky planet inward of the snow line. Despite this low volatility, early analysis of Apollo samples demonstrated that $\mathrm{P}$ is mobilized by impacts and undergoes significant redox changes (Ramdohr and El Goresy 1970, Cirlin and Housley 1980). Although a majority of $\mathrm{P}$ is in phosphate minerals on the Moon, a non-negligible portion of $\mathrm{P}$ is dissolved in metal or is present as the mineral schreibersite, $(\mathrm{Fe}, \mathrm{Ni})_{3} \mathrm{P}$. Some of this material may have been delivered from exogenous meteoritic material (Goldstein and Yakowitz 1971), and other material may have been formed via the in situ reduction of phosphates (El Goresy et al. 1971, 1972).

Phosphorus as phosphate minerals are an important part of the lunar mineral and compositional inventory (Snyder et al. 1992), and the petrologic and geochemical features of $\mathrm{P}$ minerals help constrain volatile processes that have occurred through the history of the Moon. Phosphorus is a major component of potassium, rare earth element, phosphorus enriched material (KREEP material), with this material containing many of the incompatible elements during magma crystallization. The phosphate minerals also bear some portion of the volatiles, as the mineral apatite, $\mathrm{Ca}_{5}\left(\mathrm{PO}_{4}\right)_{3}(\mathrm{OH}, \mathrm{F}, \mathrm{Cl})$ is a minor constituent of the lunar phosphate minerals, and traps some portion of the lunar volatiles. The distribution of these volatiles within phosphates and elsewhere has been well studied by McCubbin et al. (2010a, b, 2011), Barnes et al. (2014), Elardo et al. (2014) and Tartese et al. (2014). 
Phosphorus reacts with metal to form phosphides due to its siderophilic character at high temperature. The most common phosphide mineral is schreibersite, though several minerals with metals other than iron and nickel, and metal to $\mathrm{P}$ ratios other than 3 to 1 are known from meteorites (Table 1). The process of volatilization and reduction of $\mathrm{P}$ in the lunar setting by impacts is unclear, but may provide constraints on the P inventory of the Moon, and potentially of other volatiles that may influence $\mathrm{P}$ reduction.

The Apollo missions sampled a small percentage of the rock types on the Moon. It is unclear if schreibersite is common to the lunar surface. Establishing the formation pathway of lunar schreibersite will constrain its modal extent on the moon, and might also assist resource utilization. Phosphorus is a key element for in situ resource utilization as $\mathrm{P}$ is necessary for plant growth and serves as a nutrient for vertebrate organisms. The efficient extraction of $\mathrm{P}$ from lunar regolith will be an important part of maintaining food supplies should a colony ever begin on the Moon. The P sources available include both the KREEP material in igneous rocks, as well as phosphides distributed amongst the lunar fines. Extracting phosphate from these two sources would require vastly different approaches.

\subsection{Characterization of phosphides and associated metal}

Schreibersite is almost exclusively an extraterrestrial mineral, common to nearly all meteorite types (Pasek and Lauretta 2008). It occurs in both asteroids and comets (Brownlee et al. 2012). Schreibersite typically contains more Ni than the metals with which it is associated (Goldstein and Yakowitz 1971). Schreibersite first crystallizes in the iron-phosphorus system at $\sim 1439 \mathrm{~K}$ if the metal bears more than $17 \% \mathrm{P}$ by mole fraction (Doan and Goldstein 1970, Morita and Tanaka 1986). For P-poor metals, schreibersite crystallizes at the eutectic 
temperature of $1321 \mathrm{~K}$. These temperatures provide the upper temperature bounds for these thermodynamic and kinetic calculations to follow. Iron metal is often related by direct contact with schreibersite in Lunar samples and hence the two minerals influence each other's composition.

Iron-nickel metal and schreibersite are ubiquitous trace minerals within lunar impact breccias, and are common to all the Apollo sample site locales (Taylor 1975). The amount of schreibersite varies with location. The largest concentration of schreibersite is found at the Apollo 16 site: about $70 \%$ of the impact breccias bear schreibersite as the principle $\mathrm{P}$ bearing phase (Taylor and Hunter 1982). The modal abundance of schreibersite in these impact rocks ranges from between 0.1 to $0.6 \%$, in those rocks that bear schreibersite (Taylor and Hunter 1982). In contrast, schreibersite is a trace mineral in the Apollo 11 samples, observed in only a few rocks (Frondel et al. 1970) and among the lunar fines. At the Apollo 11 site, magnetic lunar fines comprise at least $0.1 \%$ of the lunar regolith (Goldstein et al. 1970).

Lunar iron metal ranges in composition from nearly pure $\mathrm{Fe}$ metal to $50 \% \mathrm{Ni}$. Phosphorus is often dissolved in metal as a solid solution, especially if no schreibersite is present. The $\mathrm{P}$ content of the metal ranges from effectively zero to greater than 2 wt. \% (Goldstein and Yakowitz 1971). Schreibersite generally occurs in contact with kamacite, $\alpha$ $\mathrm{Fe}, \mathrm{Ni}$, and the $\mathrm{P}$ content of the kamacite is typically very low as $\mathrm{P}$ diffuses out of the metal and into schreibersite. The Ni content of schreibersite, when compared to associated kamacite, has been used to establish heating histories (Doan and Goldstein 1970), though some doubt has been cast on this method (Hunter and Taylor 1982). 
Individual grains of iron-nickel metal were separated based on Co and Ni concentrations into a meteoritic group and an indigenous group (Goldstein and Yakowitz 1971), though this grouping was later called into question (Taylor et al. 1976). Paradoxically, many of these metals bear higher $\mathrm{P}$ and $\mathrm{C}$ than expected for a meteoritic origin despite having "meteoritic" compositions (Goldstein et al. 1970), suggesting some processing has taken place for these materials. The separation of metals into these two groups results in distributions that vary with location: those at the Apollo 12 sites are primarily indigenous $(\sim 80 \%)$, whereas those at the Apollo 16 sites are mostly meteoritic (Reed and Taylor 1974).

Schreibersite is most often associated with iron-nickel metal, but also occurs on its own as discrete angular grains within Apollo 16 basaltic rock (Grieve and Plant 1973). When schreibersite is associated with metal, it often forms a rind that surrounds the metal, and is itself often surrounded by a rind of troilite, FeS (Frondel et al. 1970, El Goresy et al. 1973, Gooley et al. 1973, Grieve and Plant 1973, Reed and Taylor 1974). This pattern may implicate phosphidation (the addition of elemental P) of metals instead of fracturing and distribution of meteoritic material. This phosphidation may itself be followed by sulfidation.

Two origins for lunar schreibersite have been proposed: reduction from in situ phosphates (El Goresy et al. 1972), and exogenous delivery from meteorites (Goldstein et al. 1970). The origin of lunar schreibersite was identified as a significant problem in lunar science (McKay et al. 1973), yet progress after the Apollo era was minimal; the formation of schreibersite on the Moon's surface remains poorly constrained. This work evaluates these proposed formation pathways for schreibersite from the purview of $\mathrm{P}$ volatilization and condensation on the lunar surface using equilibrium thermodynamics and kinetic considerations. In doing so, I attempt to 
constrain the concentration of other volatiles that may be interacting with $\mathrm{P}$ in reduction of phosphates, and identify ways by which $\mathrm{P}$ might be retrieved for in situ resource utilization.

\section{Methods}

I investigated the chemistry of schreibersite formation using the thermodynamic equilibrium modeling program HSC Chemistry (version 7.1, Outokompu Research Oy), coupled to kinetic data described below. The HSC Chemistry code uses the GIBBS energy solver (White et al., 1958) to compute equilibrium concentrations and solve for reaction mass balances, and has been used previously to constrain sulfur chemistry in the solar system (Pasek et al., 2005), and acid chemistry on Europa (Pasek and Greenberg, 2012). The code allows for the injection or removal of species, or changes to pressure or temperature, and determines the resulting species distribution with respect to composition. Reaction kinetics are ignored in this aspect of the study. The thermodynamic results predicted by this program have long been used in industry for metal and ore processing ${ }^{1}$, and results for solar system condensation sequences (Pasek et al. 2005) are consistent with prior calculations (e.g., Lodders 2003).

Two modules of this program were used in this study. In the first module, individual reactions of interest were supplied as the input data, and the mass balance of these reactions was then solved to determine the oxygen fugacity dependence of schreibersite as a function of temperature. Thermodynamic data for schreibersite comes from Zaitsev et al. (1995).

The second module determined the $\mathrm{P}$ gas speciation as a function of heating of whitlockite or merrillite, which in the program has a formula $\mathrm{Ca}_{3}\left(\mathrm{PO}_{4}\right)_{2}$, and though not identical to whitlockite or merrillite, serves as a proxy until thermodynamic data for these species is made

\footnotetext{
${ }^{1}$ See http://www.outotec.com/en/Products--services/HSC-Chemistry/ for program capabilities and history.
} 
available. These models were run with one of two buffers present: magnetite-hematite, and ironilmenite-ulvospinel. Starting compositions are entered as moles of individual species. The program then determines the equilibrium composition as a function of temperature and pressure. The temperature was varied from $773 \mathrm{~K}$ to $2273 \mathrm{~K}$, and pressure was kept at $10^{-4}$ bar, though varying the pressure did not significantly alter $\mathrm{P}$ gas speciation.

For these models, once we have supplied the abundances of the elements and pressuretemperature conditions, the HSC program calculates the distribution of elements amongst the various chemical species by solving the minimum thermodynamic energy state coupled to mass balance calculations. The species considered include the gases $\mathrm{N}_{2}, \mathrm{H}, \mathrm{H}_{2}, \mathrm{H}_{2} \mathrm{O}, \mathrm{PH}, \mathrm{O}, \mathrm{O}_{2}, \mathrm{O}_{3}, \mathrm{C}$, $\mathrm{CO}, \mathrm{CO}_{2}, \mathrm{CH}_{4}, \mathrm{P}, \mathrm{P}_{2}, \mathrm{P}_{3}, \mathrm{P}_{4}, \mathrm{PO}, \mathrm{PO}_{2}, \mathrm{P}_{2} \mathrm{O}_{3}, \mathrm{P}_{2} \mathrm{O}_{4}, \mathrm{P}_{2} \mathrm{O}_{5}$, and $\mathrm{P}_{4} \mathrm{O}_{10}$. Solids include $\mathrm{C}$ (graphite), $\mathrm{Fe}, \mathrm{FeTiO}_{3}, \mathrm{Fe}_{2} \mathrm{TiO}_{4}, \mathrm{Ca}_{3}\left(\mathrm{PO}_{4}\right)_{2}, \mathrm{CaO}, \mathrm{CaSiO}_{3}, \mathrm{SiO}_{2}, \mathrm{Fe}_{2} \mathrm{O}_{3}$, and $\mathrm{Fe}_{3} \mathrm{O}_{4}$. The starting amount of these materials were set equal to the lunar composition (e.g., $\mathrm{O} \sim 43$ wt. \%, P $1000 \mathrm{ppm}$, Heiken et al. 1991), with an excess of the buffer of interest at twice the abundance of $\mathrm{O}_{2}$.

These models set to solve for the equilibrium reduction of phosphates to phosphides, and to establish the conditions of changes in $\mathrm{P}$ chemistry. Secondly, the $\mathrm{P}$ gas speciation resulting from the heating of lunar phosphates were constrained to determine what gases might have been present during the heating and volatilization of lunar phosphates, perhaps by impact. The speciation of $\mathrm{P}$ gases determines if the phosphidation of metal can take place. Oxidized gases (e.g., $\mathrm{P}_{2} \mathrm{O}_{5}, \mathrm{P}_{4} \mathrm{O}_{10}$ ) are not able to phosphidate metal.

\subsection{Kinetics of phosphidation}

The kinetics of phosphidation were calculated using data from Sasaki (1985). In this study, the phosphidation rates of iron, nickel, and chromium metals and alloys were 
experimentally determined. These rates follow a parabolic rate law with respect to amount of time and amount of phosphide formed. Foils of these metals were reacted with $\mathrm{P}$ vapor in equilibrium with heated liquid P under varying pressures. Sasaki (1985) showed that nickel reacts with $\mathrm{P}$ the most rapidly of these metals. Additionally, metal phosphidation broadly follows the Deal-Grove model (1965) with rapid formation of a thin $(\sim 30 \mathrm{~nm})$ film of a phosphide followed by diffusion of $\mathrm{P}$ to reach the metal substrate. Since chromium phosphide is virtually unknown in meteoritics and cosmochemistry, this species was omitted from the present study.

From Sasaki's (1985) data, the rates of phosphidation of pure metals $(\mathrm{Fe}$ and $\mathrm{Ni}$ ) followed an Arrhenius relationship, calculated as:

$$
\begin{aligned}
K_{F e} & =0.459 e^{\frac{-132067}{R T}} \\
K_{N i} & =1.06 e^{\frac{-98811}{R T}}
\end{aligned}
$$

$K$ is calculated in $\left(\mathrm{kg}^{2} / \mathrm{m}^{4} \mathrm{~s}\right)$, and $\mathrm{R}$ is $8.314 \mathrm{~J} / \mathrm{mol} \mathrm{K}$. In the Deal-Grove model, the amount of material phosphidated is $\sqrt{K t}$ where $K$ is calculated above, and $t$ is the time exposed to $\mathrm{P}$ gas at this temperature in seconds. This gives the amount $(\mathrm{kg})$ of material phosphidated as a function of surface area and time.

Sasaki (1985) showed that the phosphidation rate of metals is only slightly dependent on the quantity of $\mathrm{P}$ in the gas. For example, if the pressure of $\mathrm{P}$ is decreased by a factor of 10 , the reaction rate only drops to $70 \%$ of the prior value. For iron, the phosphidation rate is proportional to $P_{P}^{0.15}$ (in Pa), and for nickel the phosphidation rate is proportional to $P_{P}^{0.10}$. In the phosphidation model investigated here, the pressure of $\mathrm{P}$ in the gases formed by impact is set to its abundance in the lunar target rock ( 1000 ppm, Heiken et al. 1991), and the gas is assumed to 
have a total pressure of $10^{-4}$ atm. The resulting $K$ values calculated above decrease by a factor of 10 for the phosphidation of iron.

\section{Formation constraint results}

The formation of schreibersite is dependent on the oxygen fugacity of the lunar environment. The reaction constraining $\mathrm{P}$ oxidation state from oxygen fugacity is taken as:

$$
2 \mathrm{Fe}_{3} \mathrm{P}+3 \mathrm{CaSiO}_{3}+2.5 \mathrm{O}_{2}=\mathrm{Ca}_{3}\left(\mathrm{PO}_{4}\right)_{2}+6 \mathrm{Fe}+3 \mathrm{SiO}_{2}
$$

where $\mathrm{Fe}_{3} \mathrm{P}$ is the iron end-member of schreibersite, and $\mathrm{Ca}_{3}\left(\mathrm{PO}_{4}\right)_{2}$ is analogous to anhydrous whitlockite. This reaction defines the $f_{\mathrm{O}_{2}}$ boundary shown as Wht-Sch on Figure 1. This $f_{\mathrm{O}_{2}}$ buffer is referenced in turn to magnetite-hematite, wüstite-magnetite, and iron-wüstite. The oxygen fugacity of the Moon has been measured at between $10^{-12.3}$ and $10^{-12.8}$ for at $1473 \mathrm{~K}$, corresponding to the iron-ilmenite-ulvospinel buffer (Sato et al. 1973). At $1473 \mathrm{~K}$ the reduction

of phosphates to schreibersite requires an $f_{\mathrm{O}_{2}}$ of $10^{-14.6}$, significantly lower than the normal $f_{\mathrm{O}_{2}}$ of Lunar material.

[FIGURE 1]

The reduction of phosphate to schreibersite is the reverse reaction and may be mediated by $\mathrm{H}_{2}$ or graphite:

$$
\begin{aligned}
& \mathrm{Ca}_{3}\left(\mathrm{PO}_{4}\right)_{2}+6 \mathrm{Fe}+3 \mathrm{SiO}_{2}+5 \mathrm{H}_{2}(\mathrm{~g})=2 \mathrm{Fe}_{3} \mathrm{P}+3 \mathrm{CaSiO}_{3}+5 \mathrm{H}_{2} \mathrm{O}(\mathrm{g}) \\
& \mathrm{Ca}_{3}\left(\mathrm{PO}_{4}\right)_{2}+6 \mathrm{Fe}+3 \mathrm{SiO}_{2}+5 \mathrm{C}=2 \mathrm{Fe}_{3} \mathrm{P}+3 \mathrm{CaSiO}_{3}+5 \mathrm{CO}(\mathrm{g})
\end{aligned}
$$


The reduction of phosphate by $\mathrm{H}_{2}$ requires a $\mathrm{H}_{2}$ to $\mathrm{H}_{2} \mathrm{O}$ ratio of greater than 30 at $1473 \mathrm{~K}$ to proceed. Graphite is a more effective reductant, and is probably limited by its abundance, rather than thermodynamics. Reduction occurs effectively if the $\mathrm{C}$ to $\mathrm{P}$ ratio is 1 to 1 by mass or more.

Phosphorus is poorly volatile even at liquidus temperatures on the Moon. The primary means of volatilizing $\mathrm{P}$ is impact. After vaporizing a rock by impact, $\mathrm{P}$ gas speciation is controlled by oxygen fugacity, which in turn is buffered by the surrounding rocks. Phosphorus will speciate primarily to $\mathrm{P}$ and $\mathrm{P}_{2}$ gases at the iron-ilmenite-ulvospinel buffer (Figure 2). In contrast, under more oxidizing conditions, $\mathrm{PO}$, and $\mathrm{PO}_{2}$, and even $\mathrm{P}_{2} \mathrm{O}_{5}$, and $\mathrm{P}_{4} \mathrm{O}_{10}$ are the dominant gases.

\section{[FIGURE 2]}

The amount of iron phosphidated was solved numerically using a middle Reimann sum method by calculating the $\sqrt{K t}$ with varying cooling rates, after adjusting the $K$ to account for the lower pressure of $\mathrm{P}$ gas. The presence of nickel in the beginning metal alloy would increase the rate of reaction; these calculations should be seen as lower limits. The temperature range over which phosphidation is expected to have occurred is 1023 (where whitlockite will start to form from reaction with the gas as shown in Figure 2) to $1321 \mathrm{~K}$ (the crystallization point at the eutectic for schreibersite). The majority of phosphidation naturally occurs at the higher temperatures, and the phosphidation of iron metal is a rapid process. Using phosphidation kinetics established by Sasaki (1985), the size of metal grains phosphidated by $\mathrm{P}$ gas as a function of cooling rate are shown as Figure 3. An iron metal particle $1 \mu \mathrm{m}$ in radius will be completely phosphidated at $1320 \mathrm{~K}$ in about twenty seconds. Even with rapid cooling rates, 
ranging from $250 \mathrm{~K} / \mathrm{s}$ to $1 \mathrm{~K} / \mathrm{s}$, as per Goldstein and Yakowitz (1971), phosphidation still proceeds appreciably.

\section{[FIGURE 3]}

\section{Discussion}

Two scenarios were proposed for the origin of schreibersite on the Moon. The first, proposed in part by Goldstein et al. (1970), is that schreibersite has a meteoritic origin. A second is that schreibersite results from the reduction of lunar phosphate material by reduced volatiles such as carbon during heating, perhaps by impact (El Goresy et al. 1972). I propose a third pathway, that phosphates form reduced $\mathrm{P}$ gas during impact heating, which subsequently phosphidates native metal to form schreibersite. This third pathway suggests that schreibersite formation is kinetically, and not thermodynamically, controlled.

Exogenous Origin. In the exogenous delivery scenario, iron meteorite impactors bombarded the Moon, with impact vaporizing or melting the impactor, which with cooling subsequently deposit the metal particles. Schreibersite formed as a result of cooling this melt, forming at the eutectic temperature $(1321 \mathrm{~K})$. Arguments for an exogenous origin include the high Ni content of schriebersite and associated metal (Goldstein et al. 1970). Since lunar Ni is relatively scarce, its high concentration in schreibersite and associated Fe-Ni metal suggested a meteoritic origin. Furthermore, the Co to Ni content of many of the metal grains and spherules fell within a meteoritic composition (Goldstein and Yakowitz 1971), although subsequent work suggested that these ratios do not remain constant during heating (Taylor et al. 1976). 
A significant line of evidence for a meteoritic origin for lunar iron-nickel metal is the enrichment of these metals with platinum group elements and other highly siderophile elements. The Ir concentration of metal grains is on the order of 1 to $10 \mathrm{ppm}$ (Palme et al. 1982), a close match to several iron meteorite groups (e.g., Pasek and Lauretta 2008). Since indigenous lunar rocks are essentially Ir-free, this Ir must come from meteorites.

A purely meteoritic origin for the lunar schreibersite and associated metal is unlikely based solely on composition. The P content of the metal fines is typically about $2 \%$ (Goldstein and Yakowitz 1971), and extremely few meteorite groups have that much (Gooley et al. 1973, McKay et al. 1973), with the IIG iron meteorites being the sole exception (Pasek and Lauretta 2008). Additionally, some of the lunar schreibersite has a composition closer to $\mathrm{Fe}_{3} \mathrm{P}$, outside of the known boundary for meteoritic schreibersite (as low as $10 \%$ in some enstatite achondrites, Wasson and Wai 1970).

Reduction Origin. Reduction of phosphates to schreibersite is known from iron ore smelting. Natural processes that form schreibersite from phosphates are inherently extraterrestrial, and hence have been hard to study. A few rare occurrences of schreibersite have been reported in the terrestrial environment, for instance when lightning reduces $\mathrm{P}$ to phosphides as it travels through soil (e.g., Essene and Fisher 1986, Pasek and Block 2009, Pasek et al. 2012). This lightning-induced redox change is likely promoted by the combustion of organics in the soil, and produces schreibersite with a formula close to $\mathrm{Fe}_{3} \mathrm{P}$.

Since the redox state of the Moon is significantly lower than that of the Earth, phosphate reduction may occur more readily. Indeed, studies of $\mathrm{P}$ reduction have shown schreibersite forms as a consequence of heating (Cirlin and Housley 1980, Yakovlev et al. 2006). 
Petrographic evidence shows schreibersite bounded by whitlockite in lunar impact breccias (El Goresy et al. 1972). Reduction of phosphates to phosphides would also enrich metal grains with $\mathrm{P}$, increasing the total $\mathrm{P}$ abundance and providing a better match to actual lunar metal composition. However, nearly all phosphate reduction reactions require reducing agents, or a low $f_{\mathrm{O}_{2}}$ (Friel and Goldstein 1976). The intrinsic $f_{\mathrm{O}_{2}}$ of lunar material is too high to promote reduction of phosphate (Sato et al. 1973, Sato 1976). Equilibrium-driven reduction of phosphate to phosphides on the Moon therefore requires reducing agents. This process may constrain the volatile inventory of the Moon, as volatiles would be the most efficient reducing agent. The quantity of volatiles required to promote phosphate reduction ( $1000 \mathrm{ppm}$ carbon, $30 \mathrm{ppm}$ of $\mathrm{H}_{2}$ ) has not been conclusively observed on the Moon, suggesting an alternative origin for this material. Alternatively these volatiles may have been lost during impact.

Impact Volatilization and Phosphidation. I present here a third scenario for the origin of lunar schreibersite. Phosphates are volatilized by impact under reducing conditions to give $\mathrm{P}$ and $\mathrm{P}_{2}$ gas (Figure 2A) at the $f_{\mathrm{O}_{2}}$ of the Moon. Reduction, in this case, is not dependent on reducing volatiles such as $\mathrm{C}$ or $\mathrm{H}$, but instead on the bulk composition of the lunar surface. After volatilization of $\mathrm{P}$, this gas reacts with metal droplets via a gas-solid reaction to form schreibersite, consistent with the results of Cirlin and Housley (1980) and Yakovlev et al (2006). These metals can have an either an indigenous or meteoritic origin, with phosphidation occurring rapidly. Diffusion of Ni to schreibersite occurs rapidly at these temperatures (Norkiewicz and Goldstein 1975, Friel and Goldstein 1976, Hewins and Goldstein 1977), forcing a mineralogic change in the metal. Schreibersite would be expected to form rinds around large iron particles as P diffuses into the metal, consistent with observed morphology (Frondel et al. 1970, El Goresy et 
al. 1973, Gooley et al. 1973, Grieve and Plant 1973, Reed and Taylor 1974, Nagel et al. 1978). The thickness of these rinds could be used to determine the cooling rate of these particles.

As a hot gas cools, schreibersite crystallizes before whitlockite at the $f_{\mathrm{O}_{2}}$ of the Moon, and this process is inherently driven by reaction kinetics and not thermodynamics. A consequence of this scenario is that schreibersite would be out of equilibrium with the bulk rock. Indeed, the experimental heating of Apollo rocks to $875^{\circ} \mathrm{C}$ results in schreibersite oxidation to whitlockite (Taylor et al. 1976). Whitlockite has been observed as an oxidation product of schreibersite in some natural lunar samples as well (El Goresy et al. 1972), likely a consequence of impact reheating. The impact-volatilization of phosphates followed by phosphidation of metal grains need not be the sole pathway to lunar schreibersite formation. Indeed, this pathway is best viewed as a modification of the in situ reduction pathway, but adds an explanation for why schreibersite occurs under conditions that would normally oxidize this material in the absence of reductants.

\subsection{P for In situ resource utilization}

Phosphorus is a key element in biological systems (Pasek and Kee 2011). For long-term colonization of the Moon, phosphate would be necessary for agriculture and for human nutrition. Presumably the efficient recycling of phosphate in a lunar colony would minimize the long-term phosphate requirement, but the initial cost might be significant, especially if this fertilizer is transported to the colony from the Earth. In situ utilization of $\mathrm{P}$ resource would enhance the sustainability and long-term survivability of a lunar colony. 
Two major hurdles face in situ $\mathrm{P}$ resource utilization on the Moon: identification and mining of ore bodies, and processing of ore material to $\mathrm{P}$ fertilizer. Phosphate is typically applied as fertilizer as ammonium phosphate, potassium phosphate, or acidic calcium phosphate salt. In Florida (Mosaic 2014), the process of phosphate extraction proceeds by reaction of phosphate ore rock (apatite) with sulfuric acid to make gypsum and phosphoric acid:

$$
\mathrm{Ca}_{5}\left(\mathrm{PO}_{4}\right)_{3} \mathrm{OH}+5 \mathrm{H}_{2} \mathrm{SO}_{4}+9 \mathrm{H}_{2} \mathrm{O}=5 \mathrm{CaSO}_{4} \times 2 \mathrm{H}_{2} \mathrm{O}+3 \mathrm{H}_{3} \mathrm{PO}_{4}
$$

Sulfuric acid is produced by burning elemental sulfur in $\mathrm{O}_{2}$ and water. Phosphoric acid is subsequently reacted with ammonia to make ammonium phosphate. Gypsum is a waste product. To be a profitable venture, the phosphate mineral needs to comprise at least $30 \%$ of the ore rock, and the energy and material requirements can be significant.

To form phosphoric acid on the Moon would require water, and sulfur and oxygen (to oxidize sulfide to sulfuric acid). Additionally, waste material is generated in roughly a 3:1 ratio of gypsum to phosphoric acid. These problems are surmountable, but would require both volatiles (as water) and a means of extracting phosphate from the rock, such as reaction with sulfuric acid.

Finding a lunar phosphate ore body would probably be more difficult that phosphate extraction. Phosphate ores on the Earth are generally linked to phosphogenesis in shallow marine environments (e.g., Föllmi 1996), and the absence of life and sedimentary rocks on the Moon mean that fractionation of igneous rock would be the sole source of lunar phosphate. Phosphorus is generally a minor element, and even KREEPy rocks have P concentrations of about 2000 ppm P (Heiken et al. 1991). In contrast, terrestrial ore bodies are $\sim 5$ wt. \% P. 
The alternative route would be to use schreibersite and lunar Fe-Ni metals as a $\mathrm{P}$ source. The $\mathrm{P}$ content within these materials is about $2 \mathrm{wt} . \%$. Both minerals are strongly attracted to a magnet, and could be magnetically extracted from lunar soil. Once collected, P in the metal and schreibersite oxidizes by reaction with water (Pasek and Lauretta 2005, Pasek et al. 2007), forming a mixture of primarily phosphite $\left(\mathrm{HPO}_{3}{ }^{2-}\right)$, and secondarily phosphate $\left(\mathrm{HPO}_{4}{ }^{2-}\right)$, along with $\mathrm{H}_{2}$ gas and rust as side products.

Phosphite is not accessible as a nutrient for most plants until it is oxidized by microbes to phosphate. Phosphite can be oxidized by UV light or by hydrogen peroxide, generating primarily phosphate (Pasek et al. 2008). Alternatively, recent advances have grown transgenic plants capable of using phosphite a sole P source (López-Arredondo and Herrera-Estrella 2012). These approaches suggest lunar schreibersite might be the best P resource for in situ utilization.

\section{Conclusion}

Schreibersite is a trace but ubiquitous mineral found at all Apollo sites. Here I propose the origin of much of the lunar schreibersite to be volatilization of lunar phosphates, followed by subsequent phosphidation of metal. Schreibersite should be a ubiquitous trace P mineral in lunar rocks associated with impact. Since the surface of the Moon is covered with impacts, schreibersite should be found everywhere. Schreibersite formation by P volatilization followed by phosphidation of metal may be extensible to other low $f_{O_{2}}$ planetary bodies, such as Mercury and the asteroid belt, and suggests phosphides might be a good source of $\mathrm{P}$ for in situ resource utilization. 
Acknowledgements. This work was jointly supported by NSF and the NASA Astrobiology Program, under the NSF Center for Chemical Evolution, CHE-1004570. I thank Virginia Pasek for taking the kids camping for a week so that I could get this paper researched and written. This manuscript benefited from excellent reviews from Roman Tartèse and an anonymous reviewer.

\section{References}

Barnes, J.J., Tartèse, R., Anand, M., McCubbin, F.M., Franchi, I.A., Starkey, N.A., \& Russell, S.S. (2014) The origin of water in the primitive Moon as revealed by the lunar highlands samples. Earth and Planetary Science Letters 390, 244-252.

Berzelius, J.J. (1832) Undersokning af en vid Bohumiliz i Bohmen funnen jernmassa. Kongelige Svenska Vetenskaps-Academiens Handlingar, 106-119.

Britvin, S.N., Kolomensky, V.D., Boldyreva, M.M., Bogdanova, A.N., Kretser, Y.L., Boldyreva, O.N., \& Rudashevskii, N. S. (1999) Nickelphosphide, $(\mathrm{Ni}, \mathrm{Fe})_{3} \mathrm{P}$, the nickel analog of schreibersite. Proceedings of Russian Mineralogical Society 128, 64-72.

Britvin, S.N., Rudashevsky, N.S., Krivovichev, S. V., Burns, P. C., \& Polekhovsky, Y. S. (2002) Allabogdanite, $(\mathrm{Fe}, \mathrm{Ni})_{2} \mathrm{P}$, a new mineral from the Onello meteorite: The occurrence and crystal structure. American Mineralogist 87, 1245-1249. 
Brownlee, D., Joswiak, D., \& Matrajt, G. (2012) Overview of the rocky component of Wild 2 comet samples: Insight into the early solar system, relationship with meteoritic materials and the differences between comets and asteroids. Meteoritics \& Planetary Science 47, 453-470.

Buseck, P. R. (1969) Phosphide from Meteorites: Barringerite, a New Iron-Nickel Mineral. Science 165, 169-171.

Cirlin, E. H., \& Housley, R. M. (1980) Redistribution of volatiles during lunar metamorphism. Proc. Lunar Planet. Sci. Conf. 11, 349-364.

Deal, B. E., \& Grove, A. S. (1965) General Relationship for the Thermal Oxidation of Silicon. Journal of Applied Physics 36, 3770-3778.

Doan, A. S., \& Goldstein, J. I. (1970) The ternary phase diagram, Fe-Ni-P. Metallurgical Transactions 1, 1759-1767.

El Goresy, A., Ramdohr, P., \& Medenbach, O. (1973) Lunar samples from Descartes site: Opaque mineralogy and geochemistry. Proc. Lunar Planet. Sci. Conf 4, 733-750.

El Goresy, A., Ramdohr, P., \& Taylor, L. A. (1971) The opaque minerals in the lunar rocks from Oceanus Procellarum. Proc. Lunar Planet. Sci. Conf 2, 219-235. 
El Goresy, A., Taylor, L. A., \& Ramdohr, P. (1972) Fra Mauro crystalline rocks: Mineralogy, geochemistry, and subsolidus reduction of the opaque minerals. Proc. Lunar Planet. Sci. Conf 3, 333-349.

Elardo, S. M., Shearer, C. K., Fagan, A. L., Borg, L. E., Gaffney, A. M., Burger, P. V., Neal, C.R., Fernandes, V.A., \& McCubbin, F. M. (2014) The origin of young mare basalts inferred from lunar meteorites Northwest Africa 4734, 032, and LaPaz Icefield 02205.Meteoritics \& Planetary Science 49, 261-291.

Essene, E. J., \& Fisher, D. C. (1986) Lightning strike fusion: extreme reduction and metalsilicate liquid immiscibility. Science 234, 189-193.

Fegley Jr B., Lewis J.S. (1980) Volatile element chemistry in the solar nebula: Na, K, F, Cl, Br, and P. Icarus 41, 439-455.

Föllmi, K. B. (1996) The phosphorus cycle, phosphogenesis and marine phosphate-rich deposits. Earth-Science Reviews 40, 55-124.

Friel, J. J., \& Goldstein, J. I. (1976) An experimental study of phosphate reduction and phosphorus bearing lunar metal particles. Proc. Lunar Planet. Sci. Conf 7, p. 272-274.

Frondel, C., Klein Jr, C., Ito, J., \& Drake, J. C. (1970) Mineralogical and chemical studies of Apollo 11 lunar fines and selected rocks. Proc. Lunar Planet. Sci. Conf 1, 445-474. 
Goldstein, J. I., Henderson, E. P., \& Yakowitz, H. (1970). Investigation of lunar metal particles. Proc. Lunar Planet. Sci. Conf 1, 499-512.

Goldstein, J. I., \& Yakowitz, H. (1971) Metallic inclusions and metal particles in the Apollo 12 lunar soil. Proc. Lunar Planet. Sci. Conf 2, 177-191.

Gooley, R. C., Brett, R., \& Warner, J. L. (1973) Crystallization history of metal particles in Apollo 16 rake samples. Proc. Lunar Planet. Sci. Conf 4, 799-810.

Grieve, R. A. F., \& Plant, A. G. (1973). Partial melting on the lunar surface, as observed in glass coated Apollo 16 samples. Proc. Lunar Planet. Sci. Conf 4, 667-679.

Heiken, G., Vaniman, D., \& French, B. M. (Eds.). (1991). Lunar sourcebook: A user's guide to the Moon. CUP Archive.

Hewins, R. H., \& Goldstein, J. I. (1977). Cooling rates for lunar samples determined with a diffusion model for phosphide exsolution. Proc. Lunar Planet. Sci. Conf 8, 1625-1638.

Hunter, R. H., \& Taylor, L. A. (1982). Rust and schreibersite in Apollo 16 highland rocksManifestations of volatile-element mobility. Proc. Lunar Planet. Sci. Conf 12, 253-259. 
Ivanov, A. V., Zolensky, M. E., Saito, A., Ohsumi, K., Yang, S. V., Kononkova, N. N., \& Mikouchi, T. (2000) Florenskyite, FeTiP, a new phosphide from the Kaidun meteorite. American Mineralogist 85, 1082-1086.

Lodders, K. (2003) Solar system abundances and condensation temperatures of the elements. Astrophys. J. 591, 1220-1247.

López-Arredondo, D. L., \& Herrera-Estrella, L. (2012). Engineering phosphorus metabolism in plants to produce a dual fertilization and weed control system. Nature biotechnology 30, 889893.

Ma, C., Beckett, J. R., \& Rossman, G. R. (2009). Discovery of a new phosphide mineral, monipite (MoNiP), in an Allende Type B1 CAI. Meteoritics and Planetary Science, 44(S7), A127.

McCubbin, F. M., Steele, A., Hauri, E. H., Nekvasil, H., Yamashita, S., \& Hemley, R. J. (2010a) Nominally hydrous magmatism on the Moon. Proceedings of the National Academy of Sciences 107, 11223-11228.

McCubbin, F. M., Steele, A., Nekvasil, H., Schnieders, A., Rose, T., Fries, M., ... \& Jolliff, B. L. (2010b) Detection of structurally bound hydroxyl in fluorapatite from Apollo Mare basalt 15058, 128 using TOF-SIMS. American Mineralogist 95, 1141-1150. 
McCubbin, F. M., Jolliff, B. L., Nekvasil, H., Carpenter, P. K., Zeigler, R. A., Steele, A., ... \& Lindsley, D. H. (2011) Fluorine and chlorine abundances in lunar apatite: Implications for heterogeneous distributions of magmatic volatiles in the lunar interior. Geochimica et Cosmochimica Acta 75, 5073-5093.

McKay, G. A., Kridelbaugh, S. J., \& Weill, D. F. (1973). The occurrence and origin of schreibersite-kamacite intergrowths in microbreccia 66055. Proc. Lunar Planet. Sci. Conf 4, 811-818.

Morita, Z. I., \& Tanaka, T. (1986). Equilibrium distribution coefficient of phosphorus in iron alloys. Transactions of the Iron and Steel Institute of Japan 26, 114-120.

Mosaic. Retrieved from http://www.mosaicco.com/florida_phosphate_operations.htm April 15, 2014.

Nagel, K., El Goresy, A., \& Grögler, N. (1978). Chemical investigations of impact features on sample 12001, 520. Proc. Lunar Planet. Sci. Conf 9, 2485-2493.

Norkiewicz, A. S., \& Goldstein, J. I. (1975). Ternary dissolution kinetics in the Fe-Ni-P system. Metallurgical Transactions A 6, 891-900.

Palme, H., Spettel, B., Wanke, H., Borchardt, R., \& Stoffler, D. (1982). Can Metal Segregation Remove Siderophiles from Lunar Impact Melts? Proc. Lunar Planet. Sci. Conf 13, 609-610. 
Pasek, M.A. (2008). Rethinking early Earth phosphorus geochemistry. Proceedings of the National Academy of Sciences USA 105, 853-858.

Pasek, M.A., \& Block, K. (2009). Lightning-induced reduction of phosphorus oxidation state. Nature Geoscience 2, 553-556.

Pasek, M.A., Block, K., \& Pasek, V.D. (2012). Fulgurite morphology: a classification scheme and clues to formation. Contributions to Mineralogy and Petrology 164, 477-492.

Pasek, M.A., Dworkin, J.P., \& Lauretta, D.S. (2007). A radical pathway for organic phosphorylation during schreibersite corrosion with implications for the origin of life. Geochimica et Cosmochimica Acta 71, 1721-1736.

Pasek, M.A., \& Greenberg, R. (2012). Acidification of Europa's subsurface ocean as a consequence of oxidant delivery. Astrobiology 12, 151-159.

Pasek, M.A., \& Kee, T.P. (2011). Origins of Phosphorylated Biomolecules. In Origins of Life: The Primal Self-organization (Eds. Egel, R., D.-H. Lankenau, and A. Y. Mulkidjanian). Springer Verlag, Heidelberg, p. 57-84. 
Pasek, M.A., Kee, T.P., Bryant, D.E., Pavlov, A.A., \& Lunine, J.I. (2008). Production of potentially prebiotic condensed phosphates by phosphorus redox chemistry. Angewandte Chemie International Edition 47, 7918-7920.

Pasek, M.A. \&Lauretta, D.S. (2008) Extraterrestrial flux of potentially prebiotic C, N, and P to the early Earth. Origins of Life and Evolution of Biospheres 38, 5-21.

Pasek, M.A., Milsom, J.A., Ciesla, F.J., Lauretta, D.S., Sharp, C., \& Lunine, J.I. (2005). Sulfur chemistry in protoplanetary nebulae with time-varying oxygen abundances. Icarus 175, 1-14.

Pratesi, G., Bindi, L., \& Moggi-Cecchi, V. (2006). Icosahedral coordination of phosphorus in the crystal structure of melliniite, a new phosphide mineral from the Northwest Africa 1054 acapulcoite. American Mineralogist 91, 451-454.

Ramdohr, P., \& El Goresey, A. (1970). Opaque minerals of the lunar rocks and dust from Mare Tranquillitatis. Science 167, 615-618.

Reed, S. J. B. (1968). Perryite in the Kota-Kota and South Oman enstatite chondrites. Mineral. Mag 36, 850-854.

Reed, S. J. B., \& Taylor, S. R. (1974). Meteoritic metal in Apollo 16 samples. Meteoritics 9, 2334. 
Sasaki, Y. (1985). The Phosphidation Behavior of Iron-Chromium-Nickel Ternary

Alloys. Trans. Jpn. Inst. Met. 26, 737-746.

Sato, M. (1976, March). Oxygen fugacity values of some Apollo 16 and 17 rocks. Proc. Lunar Planet. Sci. Conf 7, 758-760.

Sato, M., Hickling, N. L., \& McLane, J. E. (1973). Oxygen fugacity values of Apollo 12, 14, and 15 lunar samples and reduced state of lunar magmas. Proc. Lunar Planet. Sci. Conf 4, p. 10611079.

Snyder, G. A., Taylor, L. A., Liu, Y. G., \& Schmitt, R. A. (1992). Petrogenesis of the western highlands of the moon-Evidence from a diverse group of whitlockite-rich rocks from the Fra Mauro formation. Proc. Lunar Planet. Sci. Conf. 22, 399-416.

Tartèse, R., Anand, M., McCubbin, F. M., Elardo, S. M., Shearer, C. K., \& Franchi, I. A. (2014). Apatites in lunar KREEP basalts: The missing link to understanding the $\mathrm{H}$ isotope systematics of the Moon. Geology 42, 363-366.

Taylor, L. A., \& Hunter, R. H. (1982). The significance of Cl/P2O5 ratios from lunar samples. Proc. Lunar Planet. Sci. Conf 12, 323-331. 
Taylor, L. A., Misra, K. C., \& Walker, B. M. (1976, April). Subsolidus reequilibration, grain growth, and compositional changes of native FeNi metal in lunar rocks. Proc. Lunar Planet. Sci. Conf. 7, 837-856).

Taylor, S. R. (1975). Lunar science: A post-Apollo view. Lunar science: A post-Apollo view, 1.

Wasson, J. T., \& Wai, C. M. (1970). Composition of the metal, schreibersite and perryite of enstatite achondrites and the origin of enstatite chondrites and achondrites. Geochimica et Cosmochimica Acta 34, 169-184.

White W.B., Johnson S.M., Dantzig G.B. (1958) Chemical Equilibrium in Complex Mixtures. The Journal of Chemical Physics 28, 751-755.

Yakovlev, O. I., Dikov, Y. P., \& Gerasimov, M. V. (2006). Experimental data on the thermal reduction of phosphorus and iron and their significance for the interpretation of the impact reworking of lunar materials. Geochemistry International 44, 847-854.

Zaitsev A.I., Dobrokhotova Z.V., Litvina A.D., Mogutnov B.M. (1995) Thermodynamic properties and phase equilibria in the Fe-P system. J. Chem. Soc., Faraday Trans. 91, 703-712.

Zolensky, M., Gounelle, M., Mikouchi, T., Ohsumi, K., Le, L., Hagiya, K., \& Tachikawa, O. (2008). Andreyivanovite: A second new phosphide from the Kaidun meteorite. American Mineralogist 93, 1295-1299. 
Table 1. Meteoritic phosphide minerals. The meteorite class each mineral was first found in is also identified, with the exception of those found in the Kaidun meteorite, as Kaidun does not fall easily within a specific meteorite class.

\begin{tabular}{llll} 
Mineral Name & Formula & First Found in & Ref \\
\hline Schreibersite & $(\mathrm{Fe}, \mathrm{Ni})_{3} \mathrm{P}$ & Iron & Berzelius (1832) \\
Perryite & $(\mathrm{Ni}, \mathrm{Fe})_{8}(\mathrm{Si}, \mathrm{P})_{3}$ & $\mathrm{E}$ chondrite & Reed (1968) \\
Barringerite & $(\mathrm{Fe}, \mathrm{Ni})_{2} \mathrm{P}$ (hexagonal) & Pallasite & Buseck (1969) \\
Nickelphosphide & $(\mathrm{Ni}, \mathrm{Fe})_{3} \mathrm{P}$ & Iron & Britvin et al. (1999) \\
Florenskyite & $\mathrm{Fe}(\mathrm{Ti}, \mathrm{Ni}) \mathrm{P}$ & Kaidun & Ivanov et al. (2000) \\
Allabogdanite & $(\mathrm{Fe}, \mathrm{Ni})_{2} \mathrm{P}($ orthorhombic) $)$ & Iron & Britvin et al. (2002) \\
Melliniite & $(\mathrm{Ni}, \mathrm{Fe})_{4} \mathrm{P}$ & Acapulcoite & Pratesi et al. (2005) \\
Andreyivanovite & $\mathrm{FeCrP}$ & Kaidun & Zolensky et al. (2008) \\
Monipite & $\mathrm{MoNiP}$ & CV chondrite & Ma et al. (2014) \\
\hline
\end{tabular}


Figure 1. Oxygen fugacity dependence on mineral buffers as a function of temperature. $\mathrm{MH}$ is magnetite-hematite, WM is wustite-magnetite, and IW is iron-wustite. The $f_{O_{2}}$ measure of lunar rock of Sato et al. (1973) is also shown.

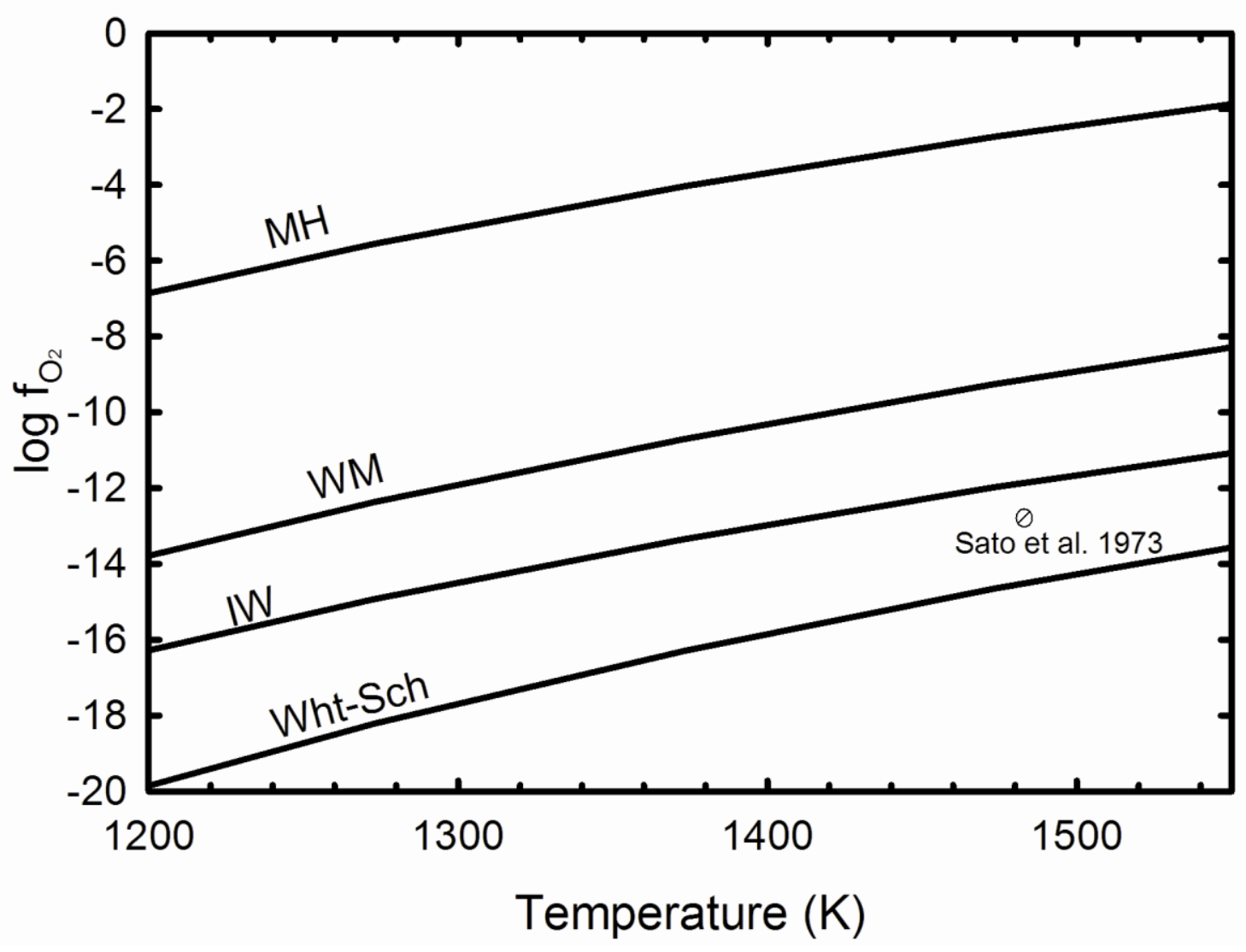


Figure 2. Gas phase chemistry resulting from the heating of whitlockite at $10^{-4}$ bar of pressure and the oxygen fugacity buffer defined by A) iron-ilmenite-ulvospinel, and B) magnetitehematite. $\mathrm{P}_{2}, \mathrm{P}_{4}, \mathrm{PO}_{2}, \mathrm{PO}$, and $\mathrm{P}$ are gases, Wht is whitlockite.
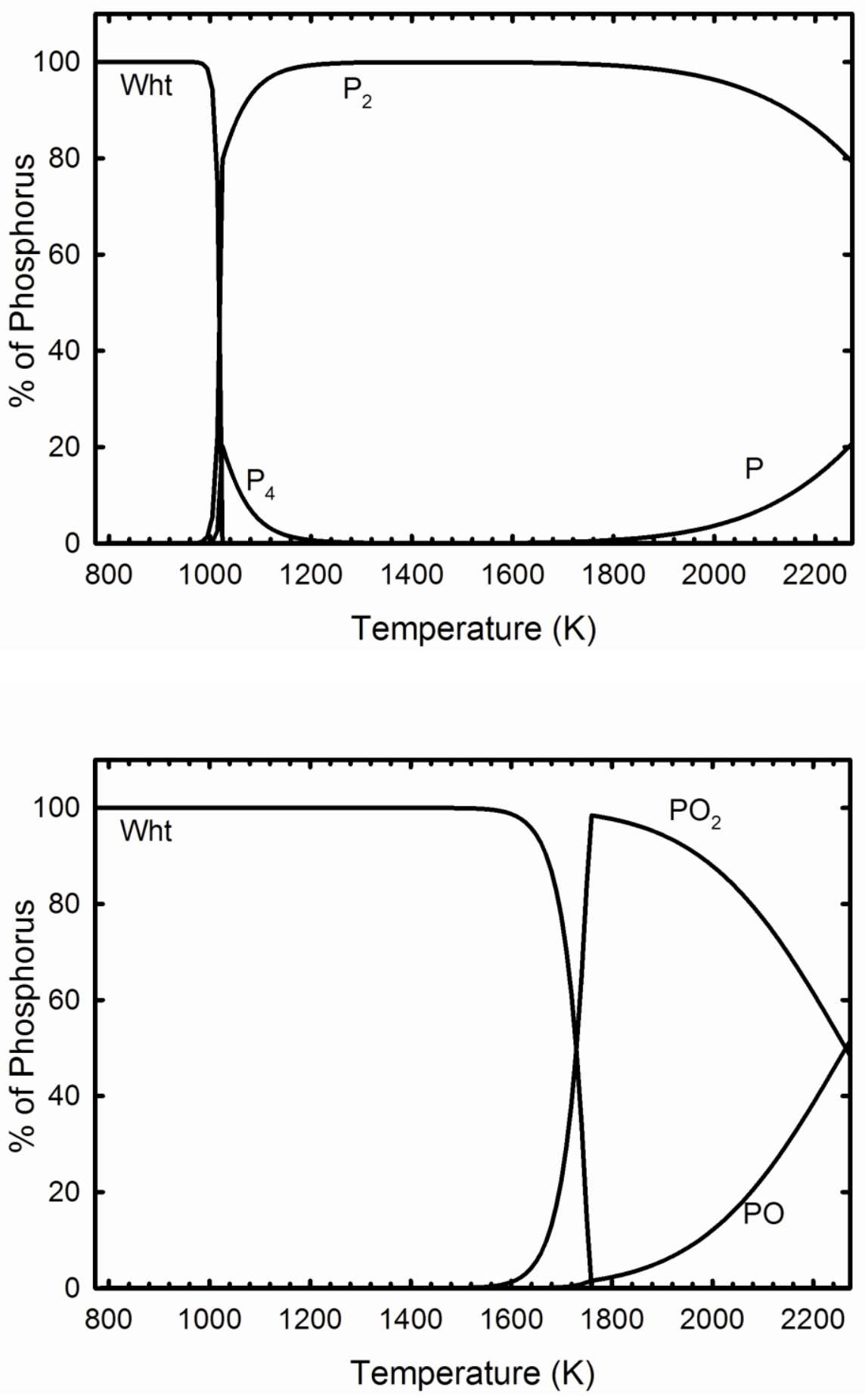
Figure 3. Fraction of metal phosphidated as a function of cooling rate, for particles cooling from $1321 \mathrm{~K}$ to $1023 \mathrm{~K}$. Particles are assumed to be spherical, and the partial pressure of $\mathrm{P}$ in the gas phase is assumed to be constant.

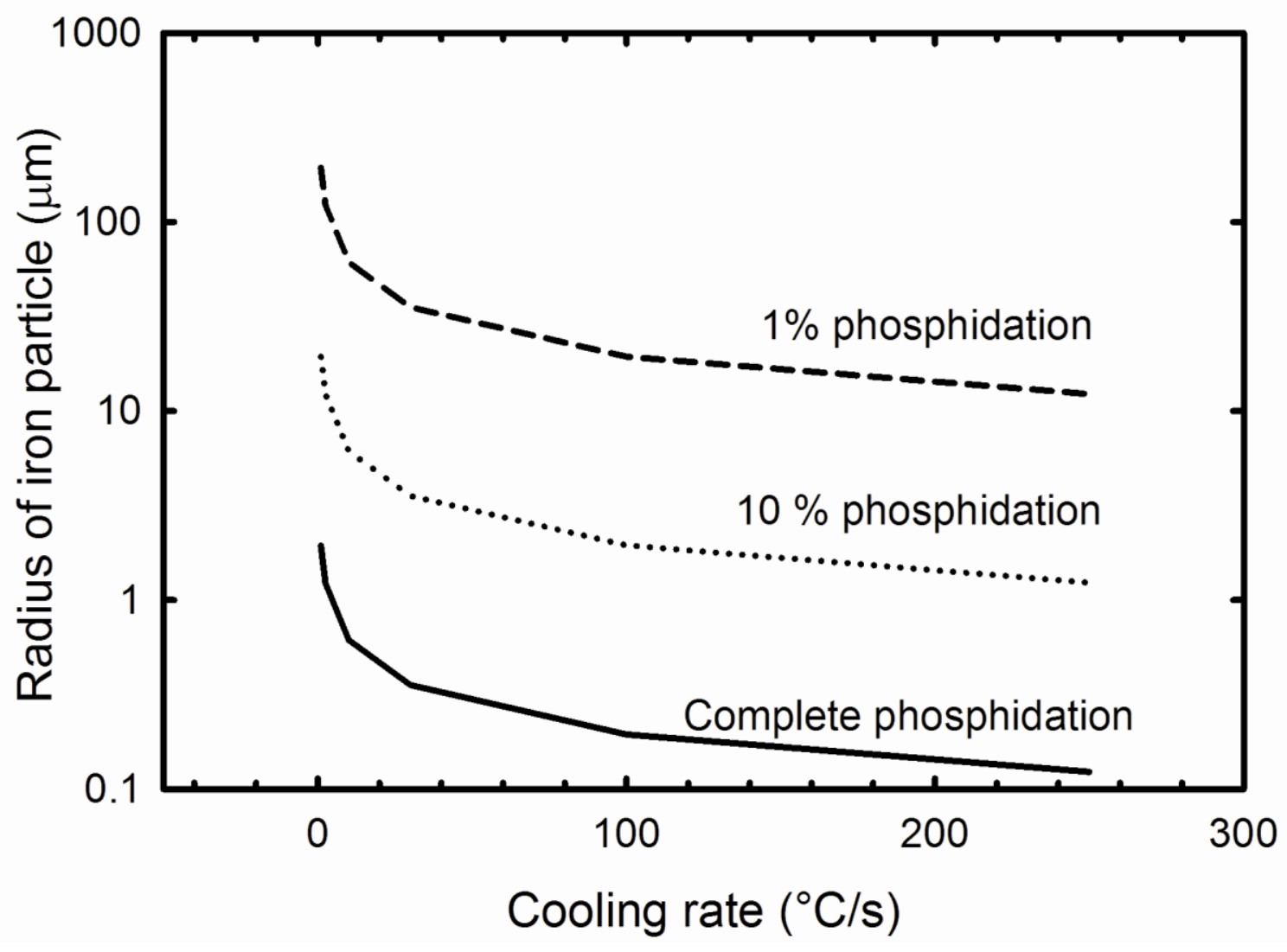

